\title{
Australian intern pharmacists' perceived preparedness for practice, and their expectations and experiences of the internship year and future career intentions
}

\author{
This article was published in the following Dove Press journal: \\ Integrated Pharmacy Research and Practice \\ 25 November 2013 \\ Number of times this article has been viewed
}

Vivienne SL Mak ${ }^{1,2}$

Geoff March ${ }^{2}$

Alice Clark ${ }^{2}$

Andrew L Gilbert ${ }^{2}$

'Department of Pharmacy Practice, School of Pharmacy, International Medical University, Kuala Lumpur, Malaysia; ${ }^{2} \mathrm{Quality}$ Use of Medicines and Pharmacy Research Centre, Sansom Institute for Health Research, School of Pharmacy and Medical Sciences, University of South Australia, Adelaide, SA, Australia
Correspondence: Vivienne SL Mak Department of Pharmacy Practice, School of Pharmacy, International Medical University, No 126, Jln Jalil Perkasa 19, Bukit Jalil, Kuala Lumpur 57000, Malaysia Tel +603 273 I 724I

Email viviennemak@imu.edu.my
Background: A key objective of Australia's health care reform is a skilled, flexible, and welltrained workforce. To meet these requirements, the training of health professionals, including pharmacists, needs to be focused on patient care processes, and students must develop competencies in the delivery of patient care. Pharmacy graduates need to be well prepared for new and alternative career pathways through their education and training, to be a part of the future workforce. This study explores Australian intern pharmacists' perceived preparedness for practice, the match between their expectations and experience to meet the requirements of health professionals in Australia's health care reforms, and their future career intentions.

Methods: Two questionnaires were sent by post to all 136 intern pharmacists in South Australia; one was sent early in their internship and the second follow-up questionnaire was sent near the completion of their internship.

Results: Pharmacy graduates felt prepared for patient care, medicines information, and primary health care roles. A mismatch between expectations and actual experiences was found. By the end of the internship, $45 \%$ agree/strongly agree that they wanted to do something else other than being a practicing pharmacist.

Conclusion: The current internship model no longer meets the needs and expectations of knowledgeable and skilled pharmacy graduates. An alternative internship model, which considers the expectations of graduates, is required.

Keywords: intern pharmacist, preparedness, expectations, experiences, internship, future career

\section{Introduction}

A key objective of Australia's health care reform is "a flexible, well-trained workforce with clear roles and responsibilities built around competencies, working together to deliver best care to patients and continuing to build their skills through effective training and team work." ${ }^{1,2}$ In order for health professionals, including pharmacists, to work effectively in this new environment, they need to be trained with the knowledge and skills to work in teams, deliver patient-centered care, and be prepared to respond to the changes required. One new environment is the formation of new regional health delivery units (Medicare locals), which are designed to better integrate and coordinate health care services amongst primary health care organizations across Australia. ${ }^{3}$ As a consequence, pharmacists are required to contribute in new and novel practice areas. To meet these requirements, the training of health professionals, including pharmacists, 
needs to be focused on mastering patient care processes as part of developing competencies in the delivery of patient care. Pharmacy graduates need to be well prepared for new and alternative career pathways, such as working in a range of settings including general practice, aged care facilities, and private residences. New approaches to their education and training will be required.

Currently, community pharmacies in Australia are remunerated by the Australian government (mainly for the supply of medicines) and income generated through the sales of nonprescription products, some of which can only be sold in pharmacies. ${ }^{4}$ Therefore, the focus of community pharmacy practice in Australia is a combination of high throughput of prescriptions and retail sales. A funding model that is predominantly based on payment per prescription ${ }^{4}$ encourages the dispensing process to be treated solely as a technical supply of medicines rather than one component in a patient care process. Providing no, or minimal, professional advice saves time which can be devoted to dispensing medicines thereby increasing the business profitability. Concentrating on technical and retailing activities does not allow the full application of pharmacists' skills or their knowledge, meaning they are an expensive, valuable, but underutilized resource in health care and in the community. There is the risk that pharmacy graduates may feel disillusioned and dissatisfied with the reality of community pharmacy practice if their expectations to deliver patient care are not met. ${ }^{5-7}$ This dissatisfaction may ultimately affect the retention rate among pharmacists. ${ }^{8-10}$

The principal pharmacy degree in Australia is the 4-year Bachelor of Pharmacy undergraduate program. Pharmacy placement activities in South Australia are currently only conducted in the fourth (final) year of the pharmacy program and last no longer than 8 weeks in total. This is followed by the internship year after graduation from the pharmacy degree program. This internship year has traditionally been used to increase clinical exposure as a step in demonstrating competence as an entry level pharmacist to the Pharmacy Board of Australia. In the UK, pharmacist education and training is similar to that in Australia, where students complete a 4-year undergraduate Master of Pharmcy (MPharm) and then have the opportunity to work with other health professionals during their preregistration (internship) year. ${ }^{11}$ Pharmacy graduates' perceived preparedness to practice in a real setting may be compromised due to the lack of experience in a practice setting during their undergraduate years.

In Australia, pharmacy graduates must successfully complete a 1-year internship prior to registration as a pharmacist. This includes a period of supervised practice while concurrently completing an Intern Training Program (ITP). ${ }^{12}$ The supervised practice, predominantly carried out in a community pharmacy or a hospital, is where competency to practice as a registered pharmacist is determined by the Pharmacy Board of Australia. However, intern pharmacists work and train within a paid employer/ employee relationship, which restricts them to an internship model where they are tied to the practice site that pays their salary for the entire training year. They are therefore unable to experience practice in different areas and sectors of a health care service. For example, interns employed to undertake supervised practice within a community pharmacy in a metropolitan area will not usually have the opportunity to experience practice in a rural setting or hospital sector. In addition, only pharmacists who are accredited are able to conduct Home Medication Reviews. If there is no accredited pharmacist at the supervision site, they will also miss the opportunity to learn about this area of professional activity. In contrast, medical interns are required to undertake rotations in different areas of practice, which have been found to be valuable in fostering their career development. ${ }^{13-15}$ General practice rotations have been found to be valuable to medical interns, who report that through rotations, they are able to experience a wide range of conditions which are not normally seen in teaching hospitals; this fosters their development as generalist doctors. ${ }^{13}$ Intern pharmacists are not given such opportunity during their internship, and as a consequence, develop skills only in the sector in which they undertake their training. This limitation will inhibit the preparation of early career pharmacists in terms of having the early experience of alternative approaches to patient care and exposure to different team care arrangements. This was shown in an Australian study where it was found that pharmacists showed reservations and lack experience in other models of practice. ${ }^{16}$ If training sites do not offer interns the opportunity to be involved in health care teams and to provide patient care, expectations of intern pharmacists to deliver patient-centered care may not be met and potentially influence their future career intentions. The link between unrealistic expectations, dissatisfaction, and disillusionment has been reported previously. ${ }^{5,8,17-19}$

In the UK, graduates indicated that their education provided them with the skills to deliver patient-centered care, good clinical knowledge, and team-working skills. ${ }^{20}$ In addition, intern pharmacists felt highly confident in drug supply and drug knowledge. ${ }^{21}$ There are currently no published 
Australian studies examining the expectations of interns for their internship year and experiences following their intern year. However, due to the similarities in pharmacist education and training in the UK and Australia, Australian graduates may express similar ideas to their UK counterparts. The aim of this study was to explore firstly, Australian intern pharmacists' perceived preparedness for practice; secondly, the match between their expectations and experience with regard to the action, skills, or resources required by them to meet the requirements of health professionals in Australia's health care reforms; and thirdly, to ascertain their future career intentions.

\section{Materials and methods}

This study was conducted in 2010, with all 136 South Australian interns enrolled in South Australian ITPs. The ITPs commence in January and end in December. Ethics approval for the study was provided by the University of South Australia Human Research Ethics Committee. Two questionnaires were sent by post, and interns were asked to complete one early in their internship (February) and a second, follow-up questionnaire near the completion of their intern year (October). This paper defines the questionnaire provided in the initial stages of the intern training year as questionnaire 1 and the one near completion of the training year as questionnaire 2 .

The questionnaire was derived from the 5-year longitudinal cohort study exploring the careers of newly qualified pharmacists in the UK. ${ }^{22,23}$ This was based on the similarities between the undergraduate pharmacy programs in the UK and Australia and the strong validity of the study design. Selected questions and a choice of answers were used in compiling the final questionnaire. To reflect the current roles and future requirements of pharmacists in Australia's health care reform initiatives, minor modifications were made to incorporate the Australian context. A list of ten pharmacist-related activities based on those undertaken in current Australian pharmacist practice, and those that will be required of health professionals in the future, were used to explore interns' perceived preparedness for practice and their expectations and experiences of involvement during their internship year. The list included technical and clinical activities (Table 1).

\section{Questionnaire I}

In questionnaire 1, interns were asked their sex, age, location (metropolitan, rural/remote) and sector (hospital/community) of internship. They were further asked the following
Table I Definitions of technical and clinical pharmacist-related activities used in the questionnaires

\begin{tabular}{|c|c|}
\hline $\begin{array}{l}\text { Pharmacist-related } \\
\text { activities }\end{array}$ & Definitions \\
\hline \multicolumn{2}{|l|}{ Technical activities } \\
\hline $\begin{array}{l}\text { Dispensing } \\
\text { (technical supply) }\end{array}$ & $\begin{array}{l}\text { A technical supply task (eg, putting } \\
\text { prescriptions through the computer and } \\
\text { labeling of medications). }\end{array}$ \\
\hline $\begin{array}{l}\text { Retail, nonprescription } \\
\text { activities }\end{array}$ & $\begin{array}{l}\text { Activities involving the provision and sale of } \\
\text { nonprescription items and retail activities. }\end{array}$ \\
\hline $\begin{array}{l}\text { Practice/business } \\
\text { management }\end{array}$ & $\begin{array}{l}\text { Activities involved in the running of } \\
\text { a pharmacy (eg, human resources, } \\
\text { accounting, staffing, etc). }\end{array}$ \\
\hline \multicolumn{2}{|l|}{ Clinical activities } \\
\hline Patient care role & $\begin{array}{l}\text { Activities that involve an interaction with } \\
\text { the patient (eg, counseling of patients). }\end{array}$ \\
\hline $\begin{array}{l}\text { Medicines information } \\
\text { role }\end{array}$ & $\begin{array}{l}\text { Communication about medicines and their } \\
\text { use to patients. }\end{array}$ \\
\hline $\begin{array}{l}\text { Multidisciplinary } \\
\text { team care }\end{array}$ & $\begin{array}{l}\text { A collaborative approach with other health } \\
\text { professionals in the care of a patient. }\end{array}$ \\
\hline $\begin{array}{l}\text { Accredited pharmacist } \\
\text { activities }\end{array}$ & $\begin{array}{l}\text { An accredited pharmacist is a registered } \\
\text { pharmacist that is credentialed to conduct } \\
\text { medication reviews. }{ }^{19} \text { Any activities related } \\
\text { to an accredited pharmacist including } \\
\text { observing an accredited pharmacist } \\
\text { conducting medication reviews. }\end{array}$ \\
\hline $\begin{array}{l}\text { Primary health care } \\
\text { delivery }\end{array}$ & $\begin{array}{l}\text { First level of care in the health care system; } \\
\text { community based sector. }\end{array}$ \\
\hline Secondary care & Care provided in aged care sector. \\
\hline Tertiary care & Care provided in hospital-based sector. \\
\hline
\end{tabular}

questions related to the list of ten pharmacist-related activities provided:

1. How well do you feel your university pharmacy education has prepared you to undertake these activities? (Likert scale: not prepared, not well prepared, adequately prepared, well prepared)

2. How much involvement do you expect to have during your internship year in these activities? (Likert scale: none, seldom, sometimes, often)

They were also asked to express their level of agreement on a 4-point Likert scale (strongly disagree, disagree, agree, strongly agree) to the following statements about their future career intentions:

1. I want to work as a practicing pharmacist in my current sector.

2. I want to work as a practicing pharmacist in another sector.

3. I want to work in a pharmacy role with more patient contact.

4. I want to do something else other than being a practicing pharmacist.

5. I am undecided about my future. 


\section{Questionnaire 2}

Interns were asked to consider their experiences during their intern year and to indicate how well prepared they felt for accepting the responsibilities of a registered pharmacist. They were specifically asked:

1. Having almost completed your internship, how prepared do you feel to undertake these activities? (Likert scale: not prepared, not well prepared, adequately prepared, well prepared)

2. How much involvement did you have during your internship year in these activities? (Likert scale: none, seldom, sometimes, often).

To explore any changes in future career intentions, the interns were again asked to express their level of agreement to the same five statements in questionnaire 1 . The interns were also given the opportunity to comment on their internship in a free text box at the end of the questionnaire.

\section{Questionnaire validation}

The face validity of both questionnaires was assessed. The first questionnaire was assessed by four interns, while two interns and two registered pharmacists assessed the second questionnaire. The researcher discussed any queries, concerns, and issues about interpretation of the meaning of the questions and the processes undertaken to complete the questionnaire. The questionnaire was revised to address issues raised, including readability and layout.

\section{Questionnaire distribution and collection}

To meet privacy considerations required by the University of South Australia Human Research Ethics Committee, the questionnaires were provided to each of the ITP coordinators. They designated unique codes for each intern against a master list of names to enable matching of responses to the second questionnaire. The questionnaires were mailed out by the ITP coordinators with a reply paid envelope addressed to the researcher, thus protecting the anonymity of respondents. An information sheet was provided with the questionnaires, and participants consented to participate by completing and returning the questionnaires to the researcher. The second questionnaire was also available online on Survey Monkey ${ }^{\circledR}$, and the web address to the online version of the questionnaire was made available on the information sheet accompanying the mailed questionnaire. Interns responding via Survey Monkey were required to enter their unique code online before commencing the questionnaire. Two follow-up reminders were issued: the first reminder was sent via email and the second as a postal reminder. The information gained remained anonymous and confidential.

\section{Data analysis}

Data were entered by the researcher into the Statistical Package for Social Sciences version 17 (IBM Corporation, Armonk, NY, USA). Entries were checked individually for discrepancies and any differences corrected. Descriptive statistics were used to characterize the cohort of interns. For dichotomous data, chi-square tests were used to compare groups. Wilcoxon signed-rank tests were performed to compare responses between questionnaire 1 and 2. Statistical significance was determined at the $0.05 \%$ level.

\section{Results}

\section{Demographics of respondents}

Sixty respondents (44.1\%) completed questionnaire 1, $49(36.0 \%)$ completed questionnaire 2, and 35 (25.7\%) completed both questionnaires (Table 2). The median age was 23 years for questionnaire 1 respondents, 24 years for

Table 2 Comparisons of characteristics between questionnaire I and questionnaire 2 respondents

\begin{tabular}{|c|c|c|c|c|}
\hline Characteristics & Questionnaire I & Questionnaire 2 & $\begin{array}{l}\text { Significance } \\
\text { test }^{\mathrm{a}}\end{array}$ & $\begin{array}{l}\text { Matching } \\
\text { questionnaire I and } \\
\text { questionnaire } 2\end{array}$ \\
\hline Total & 60 & 49 & & 35 \\
\hline \multicolumn{5}{|l|}{ Sex } \\
\hline Male & $16(26.7)$ & II (22.4) & $\chi_{(1)}^{2}=0.26$ & 8 (22.9) \\
\hline Female & $44(73.3)$ & $38(77.6)$ & $P=0.6 \mathrm{I}$ & $27(77.1)$ \\
\hline \multicolumn{5}{|l|}{ Sector of internship } \\
\hline Community pharmacy & $50(83.3)$ & $43(87.8)$ & $\chi_{(1)}^{2}=0.42$ & $29(82.9)$ \\
\hline Hospital pharmacy & $10(16.7)$ & $6(12.2)$ & $P=0.52$ & $6(17.1)$ \\
\hline \multicolumn{5}{|l|}{ Location of internship } \\
\hline Metropolitan area & $47(78.3)$ & $38(77.6)^{\mathrm{b}}$ & $\chi_{(1)}^{2}=0.01$ & $30(85.7)$ \\
\hline Rural/remote area & $13(21.7)$ & $10(20.4)$ & $P=0.92$ & $5(14.3)$ \\
\hline
\end{tabular}

Notes: 'Represents significance tests based on chi-square tests comparing questionnaire I and questionnaire 2 groups; ${ }^{b}$ represents the location for one respondent was not determined. 
questionnaire 2, and 24 years for respondents who completed both questionnaires.

This paper only presents results of respondents $(n=35)$ who completed both questionnaires.

\section{Perceived preparedness for practice, expectations, and experiences of the internship year}

Of the 35 individuals who completed both questionnaires, six were interns who undertook their internship in the hospital sector (Table 2). Data analyses were conducted separately for respondents in the two sectors of practice (community and hospital), as respondents might not share exactly the same experiences. For example, an intern practicing in the community sector might have limited or no involvement in "tertiary care" activities.

\section{Perceived preparedness}

Respondents in the community sector indicated that by the end of the internship year they felt significantly more prepared in "patient care" $(P=0.008)$, "multidisciplinary team care" $(P=0.020)$, "medicines information role" $(P=0.005)$ and "primary health care delivery" $(P=0.005)$ compared with their level of preparedness at the point of starting their internship year (Table 3). There was no change across the remaining variables. Respondents felt more prepared than not for variables primary health care delivery, "accredited pharmacist", and "secondary care" while they felt less prepared than not for tertiary care.

Due to the low response of those trained in the hospital sector $(\mathrm{n}=6)$, statistical analyses was not conducted. However, four respondents felt less prepared for "dispensing activities", two for patient care, secondary care, and accredited pharmacist activities by the end of the internship year. Four respondents felt more prepared for tertiary care by the end of the internship year.

\section{Expectations and experiences}

All respondents in the community sector indicated that they either had their expectations of being often involved in "dispensing activities" met $(n=25)$ or exceeded $(n=4)$ at the end of their internship (Table 4). Experience matched expectations in all other variables except for "primary health care delivery", where experience was above initial expectations, and for "accredited pharmacist" and "tertiary care", where experience was below initial expectations. Where their experiences exceeded their expectations, it meant that they had spent more time in the activity than expected.

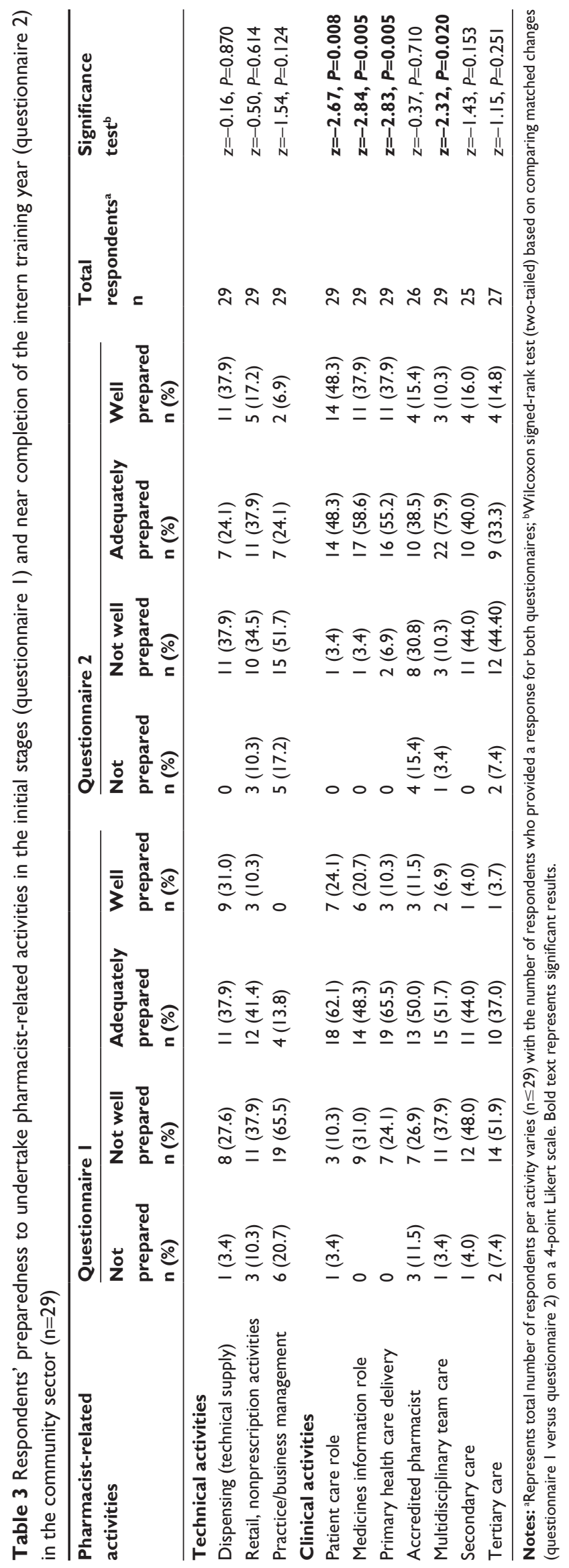




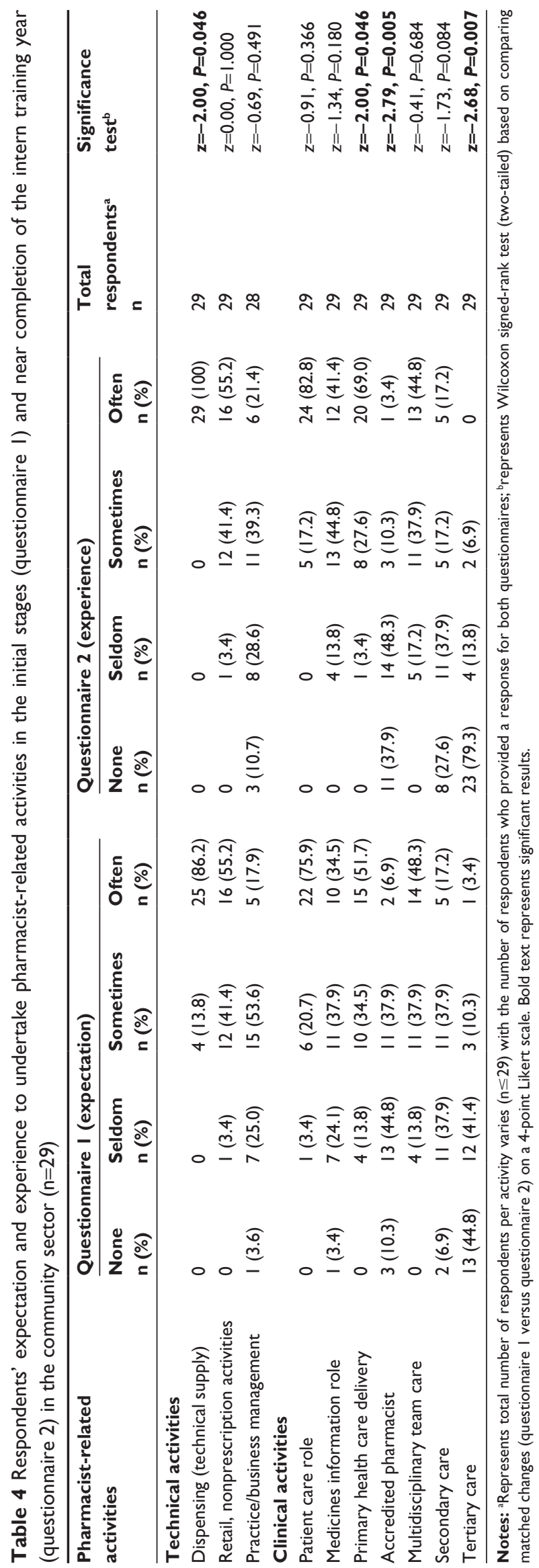

Statistical analyses was not conducted for respondents in the hospital sector $(\mathrm{n}=6)$. None of the respondents experienced "primary health care delivery". Five respondents indicated that their expectations were met for "tertiary care", while four respondents indicated that they expected more involvement in "accredited pharmacist activities" and "secondary care", but their experience was below initial expectations.

\section{Future career intentions}

Overall, there were no statistically significant changes in respondents' future career intentions between questionnaires 1 and 2. Nevertheless, $44.8 \%$ of respondents agree/strongly agree that they "want to do something else other than being a practicing pharmacist" by the end of the internship compared with $37.9 \%$ at the start of their internship (Table 5). Half of the respondents were undecided about their future by the end of the internship.

\section{Free text comments regarding their internship}

Fifteen respondents (31\%) made additional comments in questionnaire 2. Of these, three respondents indicated that the intern training year was overall a positive experience. The majority of the comments related to the lack of opportunity to apply their knowledge and clinical skills in community pharmacy (Table 6). There were also comments associated with the university pharmacy education not preparing them for the realities of practice and the high workload associated with their internship. Table 6 shows the representative quotes surrounding these comments.

\section{Discussion}

Over $80 \%$ of all respondents in both questionnaires worked in the community pharmacy sector and nearly $80 \%$ worked in a metropolitan environment. This represents well the intern pharmacist workforce distribution. Despite the high priority set by the existing practice sites on dispensing, and the high proportion of interns' time devoted to this activity, only $61 \%$ of respondents trained in the community setting felt prepared for dispensing upon registration as a pharmacist. In contrast, over $90 \%$ felt prepared for patient care, medicines information, and primary health care roles.

In the matched group, across all categories of pharmacistrelated activities, there was a trend towards greater preparedness to undertake clinical activities, patient care, medicines information role, multidisciplinary team care, and primary health care role. This indicates that the internship year had added to the preparedness of the interns to deliver the style 
Table 5 Respondents who agree/strongly agree to the following statements about their future career intentions in the initial stages (questionnaire I) and near completion of the intern training year (questionnaire 2) $(n=35)$

\begin{tabular}{llll}
\hline Statements & Agree/strongly agree & & Total \\
\cline { 2 - 3 } & Questionnaire I & $\begin{array}{l}\text { Questionnaire 2 } \\
\mathbf{n}(\%)\end{array}$ & $\begin{array}{l}\text { respondents } \\
\mathbf{n}^{\mathbf{a}}\end{array}$ \\
\hline I want to work as a practicing pharmacist in my current sector. & 3 I (96.9) & $29(90.6)$ & 32 \\
I want to work as a practicing pharmacist in another sector. & $10(66.7)$ & $10(66.7)$ & 15 \\
I want to work in a pharmacy role with more patient contact. & $30(96.8)$ & $28(90.3)$ & 3 I \\
I want to do something else other than being a practicing pharmacist. & 1 I (37.9) & $13(44.8)$ & 29 \\
I am undecided about my future. & $9(34.6)$ & $13(50.0)$ & 26 \\
\hline
\end{tabular}

Note: aRepresents total number of respondents per activity varies $(n \leq 35)$ with the number of respondents who provided a response for both questionnaires.

of practice consistent with the demands of Australia's health care reforms. ${ }^{1,3}$ Notwithstanding, regardless of intern sector, the respondents were often engaged in dispensing activities, highlighting that the supply of medicines and the consequent income generation in the community sector are prime drivers of the style of practice. Other professional activities were more setting specific; for example, all hospital sector interns were often involved in tertiary care activities, while the community sector interns were rarely engaged in that activity. Linking this with the worrying result that $67 \%$ of respondents, by the end of the intern training year, reported that they wanted to work as a practicing pharmacist in another setting, indicates that the current rigid structure of the intern year needs to be reviewed to allow interns to experience different sectors of practice. A better model could be that which is used by the medical profession, ${ }^{24,25}$ which allows for a rotation of medical interns through different practice settings, especially with government demand for work-ready health practitioners upon graduation or registration.
The internship experience did have a positive impact in developing knowledge and skills around the patient care role. Respondents felt reasonably prepared for this role; they had high expectations of participating in this activity, and all reported having at least some level of patient interaction. The ability to work directly and effectively with patients is a key aspect of any health professionals' attributes and is the foundation on which the new pharmacy services can be built. Not unexpectedly, similar findings were recorded for the medicines information role and primary health care delivery, indicating that most interns had reasonable opportunities to talk with people about their medications and minor health conditions. These three clinical activities are expected to be delivered in any community pharmacy.

There was ambivalence among respondents concerning their readiness to be a member of a health care team at the point of entering their internship; however, the expectation was that they would be exposed to this important skill through opportunities during their internship year. Their expectation of involvement was achieved even though there was uncer-

Table 6 Representative quotes from comments regarding respondents' internship

Lack of opportunity to apply their knowledge and clinical skills in community pharmacy

"Being a dispense monkey full time can get boring and nonstimulating; I find that I am looking for ways to expand my skills and knowledge but community pharmacy in the real world has very little opportunities to do so; community based practice seems to be heading down a script number and price driven field which I do not enjoy."

"Community interns often get treated like dispensary assistants. We are different to assistants in that we have 4-5 (years) of tertiary pharmacy knowledge under our belts. We should be utilized better."

"I did my internship in a community setting and was so frustrated that so much of what I had learnt at university was not applied at all in the community setting. Instead, the fast pace of the pharmacy and the high script count meant that we dispensed for a great majority of the day, with only a few counseling in between. I don't know if my expectation was perhaps unreasonable to begin with, in that I wanted to do a whole lot more counseling! It was frustrating to have a body of knowledge in your hands that you were not able to fully utilize."

"There was a lot of clinical stuff that we got taught that did not really apply to the everyday community setting."

University pharmacy education not preparing them for the realities of practice

"University does not prepare us at all for the working world or work of pharmacy. I think the university did not help with my expectation of my intern training year, it shattered it."

"I felt that the university did not adequately prepare us for the internship year. A lot of things that we do need to know such as the Pharmaceutical Benefits Scheme, how to submit a prescription claim, and more of the business side to pharmacy were not covered during university years at all."

Workload associated with internship

"We had a much higher workload for the intern training program compared to past years."

"A lot more assignments/work associated with the intern training program than expected!" 
tainty about their readiness to be a member of a health care team. Universities should strive to bolster the interprofessional learning component of their curricula to better prepare students for this necessary practice element.

The ability to identify and resolve medication-related problems should be a core attribute of pharmacists as it is likely to be their major contribution in the reformed health system. Currently, accredited pharmacists are paid to provide medication reviews in the home and aged care facilities, with the aim of identifying and resolving medication-related problems. ${ }^{26,27}$ This activity is strongly clinically grounded and requires the pharmacist to assume greater professional responsibility, greater patient involvement, and greater use of knowledge and patient care skills. It is performed in collaboration with other health professionals. Respondents were evenly split in the adequacy of preparation, and about $45 \%$ expected to experience this clinical service, but only $14 \%$ were actually involved in its provision. The low expectation level may be in part explained by the lower level of preparedness perceived by the respondents to questionnaire 1 and in part by the fact that not all community pharmacists are involved in offering the service. The low level of actual experience indicates that both the university program and the ITP and participating pharmacies do not provide the depth of knowledge, opportunity for skill development, mentoring, or exposure for the undergraduate students and interns. This lack of exposure is of concern, particularly when the one area of pharmacist practice that financially rewards them for working collaboratively with medical practitioners and patients ${ }^{26}$ is not offered to the majority of respondents. These accredited pharmacist services have a strong evidence base for their ability to reduce medicine-related hospital admissions. ${ }^{28}$ Further, the training and practice opportunities provided during the internship year are seen as valuable resource in developing the knowledge and skills acquired during the undergraduate education in achieving readiness for eventual registration. ${ }^{29}$

The responses by community pharmacy interns to the initial level of expectation of involvement in tertiary sector and the eventual lower level of experience indicates that there are misunderstandings of the current divide between community and the public sector practice, and that they entered the internship year with unrealistic expectations. However, the fact they had little experience with the tertiary sector is also a weakness in the internship training system.

Not unexpectedly, intern pharmacists in the hospital sector reported no involvement in primary health care and accredited pharmacist activities. Accredited pharmacist services are only available in the primary care area of the health system, and hospitals are explicitly excluded from the provision of this service. ${ }^{30}$
If pharmacy graduate experiences during practice were below initial expectations, it is highly likely that frustration and discontent with the profession occur. ${ }^{5,8}$ Dissatisfaction due to unrealistic expectations may cause these pharmacy graduates, with the skills and knowledge required for professional practice, to leave the profession. ${ }^{8}$ The most worrying finding was that the proportion of interns who wanted to do something else, other than being a practicing pharmacist, rose from $38 \%$ in questionnaire 1 to $45 \%$ in questionnaire 2 , and those who were undecided about their future rose from $35 \%$ to $50 \%$. An explanation for the high percentage recorded at the commencement of their internship year could be due to their inability to secure hospital internships, as there are limited sites available. However, if these findings are representative of all Australian intern pharmacists, and given the standardized nature of all ITPs for pharmacists, this may be the case, there is likely to be a high attrition rate among pharmacists in early to midcareer. This is further reiterated in another Australian study where the findings indicated that the profession may be losing both early career and experienced pharmacists. ${ }^{31}$

This dissatisfaction, brought about by the mismatch between expectations of skill development across all areas of professional practice and the actual experiences being highly focused on supply-based dispensing, with little use of acquired knowledge and skills, was further expressed in the free text comments by 15 respondents. It was also expressed that "being a dispense monkey full time can get boring and nonstimulating".

The findings from this sample South Australian cohort of intern pharmacists may not be representative of all intern pharmacists in Australia; however, the education and training programs are similar across the country, as all pharmacy programs are required to be accredited, a process which uses an indicative course structure to measure the ability of the programs to deliver graduates with the required knowledge and skills.

\section{Conclusion}

The findings suggest that the characteristics of the environment these intern pharmacists were exposed to during their internship no longer met the needs and expectations of these knowledgeable and skilled pharmacy graduates. The current internship model, where the intern is being paid a salary and thus tied to that site for their entire internship year, is outdated. Alternative models need to be developed and evaluated. In particular, such modeling should consider the expectations of graduate pharmacists, as detailed in this study, where it would lead to an internship which exposes intern pharmacists to the full range of practice settings via rotations. A rotational style of internship would provide a better match between interns' expectations and experiences with regard to the action, skills, or resources required by 
these early career pharmacists to meet the requirements of Australia's health care reforms.

\section{Acknowledgments}

This work was supported by the Sansom Pharmacy Fund, University of South Australia. The authors would like to thank all participants for their contribution to this study.

\section{Disclosure}

The authors report no conflicts of interest in this work.

\section{References}

1. Department of Health and Ageing. Building a 21st Century Primary Health Care System: Australia's Primary Health Care Strategy. Canberra: Australian Government, Department of Health and Ageing, Commonwealth of Australia; 2010. Available from: http://www.yourhealth.gov.au/ internet/yourhealth/publishing.nsf/Content/report-primaryhealth/\$File/ NPHCS-Foreword-intro.pdf. Accessed October 31, 2013.

2. Health Workforce Australia. National Health Workforce Innovation and Reform Strategic Framework for Action 2011-2015. Adelaide: Health Workforce Australia; 2011. Available from: http://www.hwa.gov.au/ sites/uploads/hwa-wir-strategic-framework-for-action-201110.pdf Accessed October 31, 2013.

3. Australian Government. A National Health and Hospitals Network for Australia's Future: Delivering the Reforms. Canberra: Australian Government, Commonwealth of Australia; 2010. Available from: http:/ www.yourhealth.gov.au/internet/yourHealth/publishing.nsf/Content/ DeliveringTheReforms/\$FILE/DeliveringTheReforms.pdf. Accessed October 31, 2013.

4. The Pharmacy Guild of Australia. Submission to the Australian Industrial Relations Commission Regarding Transitional Consultations for Pharmacy Industry Award 2010. Canberra: The Pharmacy Guild of Australia, National Secretariat; 2009. Available from: http://beta.guild.org.au/uploadedfiles/ National/Public/News_and_Events/News_Archive/20090626_PGA_ trans_further.pdf. Accessed February 4, 2013.

5. Ward PR, Seston EM, Wilson P, Bagley L. Perceived barriers to participating in continuing education: the views of newly registered community pharmacists. Int J Pharm Pract. 2000;8(3):217-224.

6. Noel MW, Hammel RJ, Bootman JL. Job satisfaction and the future of pharmacy. Am J Hosp Pharm. 1982;39(4):649-651.

7. Eden M, Schafheutle EI, Hassell K. Workload pressure among recently qualified pharmacists: an exploratory study of intentions to leave the profession. Int J Pharm Pract. 2009;17(3):181-187.

8. Mak VS, March GJ, Clark A, Gilbert AL. Why do Australian registered pharmacists leave the profession? A qualitative study. Int J Clin Pharm. 2013;35(1):129-137.

9. Gaither C. Career commitment: a mediator of the effects of job stress on pharmacists' work-related attitudes. J Am Pharm Assoc (Wash). 1999;39(3):353-361.

10. Smith SN, Stewart JE, Grussing PG. Factors influencing the rate of job turnover among hospital pharmacists. Am J Hosp Pharm. 1986;43(8): 1936-1941.

11. Pharmacist pre-registration training [webpage on the Internet]. London: General Pharmaceutical Council. Available from: http://www pharmacyregulation.org/education/pharmacist-pre-registration-training. Accessed August 15, 2013.

12. Intern Training Program Accreditation [webpage on the Internet]. Civic Square: Australian Pharmacy Council; 2010. Available from: http:/ pharmacycouncil.org.au/content/index.php?id=22. Accessed August 10, 2013.

13. Mugford BV, Braund W, Worley PS, Martin A. Rural intern training. Rural Remote Health. 2001;1(1):86.
14. Sen Gupta TK, Muray RB, McDonell A, Murphy B, Underhill AD. Rural internships for final year students: clinical experience, education and workforce. Rural Remote Health. 2008;8(1):827.

15. Grace K, Bradford CJ. Community and general practice terms for prevocational junior medical officers: experience and development in South Australia and Western Australia. Med J Aust. 2007;186(Supp1 7): S28-S30.

16. Mak VS, Clark A, Poulsen JH, Udengaard KU, Gilbert AL. Pharmacists' awareness of Australia's health care reforms and their beliefs and attitudes about their current and future roles. Int $J$ Pharm Pract. 2012;20(1):33-40.

17. Curtiss FR, Hammel RJ, Heinen JS, Johnson CA. The importance of education and practice actors in determining stress and strain among young pharmacy practitioners. Am J Pharm Educ. 1978;42:104-111.

18. Collins DM, Benson HAE, Occhipinti S, Wright A, Mcelnay JC. The impact of professional socialisation on pharmacy students' role perceptions. Int J Pharm Pract. 1999;7(3):182-187.

19. White paper on pharmacy student professionalism. American Pharmaceutical Association Academy of Students of Pharmacy - American Association of Colleges of Pharmacy Council of Deans Task Force on Professionalism. J Am Pharm Assoc (Wash). 2000;40(1):96-102.

20. Willis SC, Shann P, Hassell K. Report 5: piloting the questionnaire. London: Royal Pharmaceutical Society of Great Britain; 2006. Available from: http://www.pharmacy.manchester.ac.uk/cpws/publications/ cohortstudyreports/cohortreport5.pdf. Accessed October 12, 2012.

21. Davies JG, Bates I, Healey R, Webb DG, McRobbie D. Fit for purpose? Pharmacy graduates' perceptions of their readiness to undertake clinical pharmacy activities. Int J Pharm Pract. 2004;12(Suppl 1):R17.

22. Willis SC, Shann P, Hassell K. Career choices, working patterns and the future pharmacy workforce. Pharm J. 2006;277:137-138.

23. Willis SC, Seston E, Hassell K. Work, Employment and the Early Careers of Cohort Pharmacists. London: Royal Pharmaceutical Society of Great Britain; 2009. Available from: http://www.pharmacyresearchuk.org/ waterway/wp-content/uploads/2012/11/Work_employment_and_theearly_careers.pdf. Accessed March 4, 2012.

24. Competency-based training in medical education 2010 [webpage on the Internet]. Kingston: Australian Medical Association. Available from: http://ama.com.au/node/5977. Accessed February 5, 2012.

25. Core terms in internship 2007 [webpage on the Internet]. Kingston: Australian Medical Association. Available from: http://ama.com.au/ node/2712. Accessed February 19, 2012.

26. Pharmaceutical Society of Australia. Guidelines for pharmacists providing Home Medicines Review (HMR) services. Canberra: Pharmaceutical Society of Australia Ltd; Oct 2011. Available from: http://www.psa.org.au/download/practice-guidelines/home-medicinesreview-services.pdf. Accessed November 6, 2013.

27. Pharmaceutical Society of Australia. Guidelines for pharmacists providing Residential Medication Management Review (RMMR) and Quality Use of Medicines (QUM) services. Canberra: Pharmaceutical Society of Australia Ltd; Oct 2011. Available from: http://www.psa.org.au/ download/practice-guidelines/rmmr-and-qum-services.pdf. Accessed November 6, 2013.

28. Roughead E, Barratt J, Ramsay E, et al. The effectiveness of collaborative medicine reviews in delaying time to next hospitalization for patients with heart failure in the practice setting: results of a cohort study. Circ Heart Fail. 2009;2(5):424-428.

29. Green LW, Kreuter MW. Health Program Planning: An Educational and Ecological Approach. 4th ed. New York, NY: McGraw-Hill Companies; 2005.

30. Home Medicines Review (HMR) [webpage on the Internet]. Victoria: Department of Human Services, Commonwealth of Australia. [updated September 27, 2013]. Available from: http://www.medicareaustralia.gov. au/provider/pbs/fourth-agreement/hmr.jsp. Accessed May 30, 2012.

31. Mak VS, Clark A, March G, Gilbert AL. The Australian pharmacist workforce: employment status, practice profile and job satisfaction. Aust Health Rev. 2013;37(1):127-130. 
Integrated Pharmacy Research and Practice

Dovepress

\section{Publish your work in this journal}

Integrated Pharmacy Research and Practice is an international, peer-reviewed, open access, online journal, publishing original research, reports, reviews and commentaries on all areas of academic and professional pharmacy practice. This journal aims to represent the academic output of pharmacists and pharmacy practice with particular focus on integrated care. All papers are carefully peer reviewed stimulating pharmaceutical professionals. The manuscript management system is completely online and includes a very quick and fair peer-review system, which is all easy to use. Visit http://www.dovepress.com/testimonials.php to read real quotes from published authors.

Submit your manuscript here: http://www.dovepress.com/integrated-pharmacy-research-and-practice-journal 